\title{
Introduction to the Special Issue on Ethnographic Experiences in Learning Design
}

\author{
Jill E. Stefaniak ${ }^{1}$ · Jason K. McDonald ${ }^{2}$
}

Published online: 13 January 2022

๑) Association for Educational Communications \& Technology 2021

Ethnography is a qualitative research method used to deeply understand the social and cultural life of communities, institutions, and other settings (LeCompte \& Schenshul, 1999). Ethnography relies on participant observation to understand individuals within a given setting, in conjunction with other qualitative tools such as interviews or artifact analysis, to develop rich accounts of a phenomenon of interest. Examples may include a teacher recounting how they have implemented new instructional strategies in their classroom, an exploration of how cultural and social injustices impact learners, and the experience of using personas to inform instructional design practices. In contrast to other forms of research that might also study these issues, ethnographic studies focus on narratives, detailed observations, and careful explanation and interpretation of events, rather than summary forms of data such as surveys or test scores.

Designing instruction is very much a participatory process where instructional designers must be attuned to the needs of their learning audience and environmental factors that may influence their success. Gordon et al. (2011) suggest that instructional designers engage in ethnographic activities routinely, grounded in their prior experiences as both learners and designers. Ethnography benefits instructional design scholarship in many ways. It 1 ) provides a lens to learn about specific contexts and learning audiences, 2) supports designers in customizing learning experiences that are conducive to learning audiences' environments, and 3) identifies contextual factors that warrant specific strategies and solutions to support learning.

For this special issue, the Design and Development Division of AECT was interested in exploring ethnographic

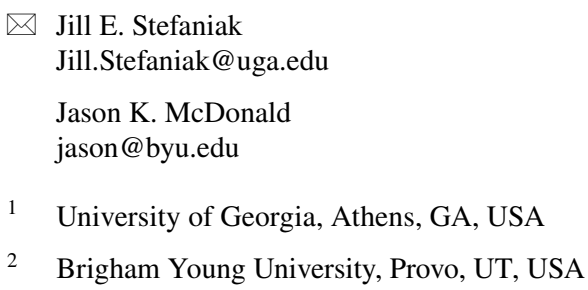

accounts of learning design in a variety of contexts. Another goal was to highlight how scholars in the field of learning, design, and technology are employing ethnographic techniques to enhance their teaching and research. We sought submissions that provided examples of ethnographic inquiry in learning design or emphasized innovative practices and/or methods of ethnographic inquiry in learning design activities. Articles were sought that provided readers with practical and applicable ideas, strategies, and techniques on topics related to the design, development, or study of learning experiences as found "in the wild."

Bowers et al. provide an autoethnographic look into the learning design process as experienced by university faculty with the assistance of an educational developer. This study contributes towards a broader view of how pragmatic the course design process can be. This was particularly the case when issues arose during a semester, where a faculty member's options to respond were highly constrained by the dynamics of the teaching situation. It also provides an important window into the affective responses faculty can experience when engaged in course design.

Boer and Asino studied a topic sure to be of current interest - the experiences of six teachers in Namibia as they coped with the ongoing COVID-19 pandemic. Two highlights of their analysis are how the teachers made the dramatic shift to emergency remote teaching, and how teachers coped with the fear and uncertainty that accompanied their challenging circumstances. This is an important view into the learning design process as it occurs when facing both heavy constraints and emotions that run high.

In a feminist autoethnography, Romero-Hall shares how she navigates the field of instructional design as an AfroLatinx woman. She provides examples of how different experiences have influenced her identity and approach to her scholarship. This paper highlights how Romero-Hall has used an intersectional feminist approach to challenge systems of oppression through her teaching and research in learning design and technology across cultures. 
Ren's autoethnography depicts the experiences of an instructional designer working in a China-U.S. collaborative program. Her paper discusses the challenges with addressing multiple cultural contexts inherent in transnational education. This study provides considerations for embodying inclusive design when working on cross-cultural design projects.

Gray's article is an analysis of the tools (both analog and digital) he has used to carry out design ethnographies. More than a review of his toolkit, however, he also provides compelling vignettes of how each tool has helped him complete his ethnographic work. This will be a valuable resource for other design ethnographers as they embark on future studies.

Banks-Weston and Kolski used an ethnographic lens to explore the impact that virtual collaboration poses on interconnectedness among a group of culturally diverse women in a strategy course. Their study found that virtual collaboration tools provided participants with a support network that could be used to support career advancement. This is particularly important for identifying opportunities to provide continued support to participants beyond the time constraints associated with courses offered in higher education settings.

In an ethnographic case study situated in an advanced instructional design course, Koehler and Meech observed how students navigate their participation through selfassessment in an online learning environment. Their study examines what intrinsic motivations support students' willingness to engage in online participation. Their findings also identify opportunities to reexamine how instructors approach the assessment of participation.
McDonald et al.'s contribution is an autoethnographic look at the experiences of university faculty teaching advanced instructional design. Teaching advanced design is a dynamic, complex endeavor, demanding that faculty nimbly move between direct instruction and forms of coaching and mentoring, based on evolving students' needs. This study also challenges some of the conventional wisdom about what are typically referred to as authentic experiences in instructional design education.

Reflecting a growing interest in computational methods for ethnographic research, Seo et al. carried out an exploratory, scoping literature review to better understand three such approaches. They were particularly interested in major methodological characteristics, similarities, and differences that have been reported in prior literature. Along with this, they discuss design implications of these methods for digital learning environments.

\section{References}

Gordon, T., Holland, J., \& Lahelma, E. (2011). Ethnographic research in educational settings. In P. Atkinson, A. Coffey, S. Delamont, J. Lofland, \& L. Lofland (Eds.), Handbook of ethnography (pp. 188-203). Sage.

LeCompte, M. D., \& Schenshul, J. J. (1999). Designing and conducting ethnography research. Altamira Press.

Publisher's Note Springer Nature remains neutral with regard to jurisdictional claims in published maps and institutional affiliations. 